DI

Department of Sleep Medicine, Royal Infirmary Edinburgh, Edinburgh, UK.

\title{
Breathe: respiration at the extremes of age
}

\section{Welcome to the March issue of Breathe!}

In this issue, we explore respiratory health and disease in the very old and the very young. Some of us have chosen to practice at the extremes of age, but many of us fall into this area by default and the range of challenges we may confront can be daunting.

Yet again, this issue brings together a variety of reviews on areas that may be problematic or pose practical dilemmas, as well as an account of the physiology of respiration in the very first days of our lives. The excellent contributions will, I hope, prove an inspirational read and I am grateful to the authors for bringing so much thought and consideration to their respective subject areas.

Some features that did not make it into print will be made available as online exclusives; you can follow the ERS Publications office on Twitter (@ERSPublications) to keep up to date.

The Junior Members Committee of the ERS continues to contribute enthusiastically with a selection of hot topics and a guide to submitting a research grant proposal, as well as an update in Junior's voice. I am grateful for their collaboration and contributions which supplement and enhance the educational content of Breathe.

We also have contributions from the Educational Activities department of ERS, with a report about an interesting educational course on thoracic imaging which took place recently in Barcelona, as well as developments from HERMES on their new respi- ratory infections project and an important update to the programme to introduce accreditation for training centres across Europe, after pilot trials in centres in Germany and Hungary.

\section{Regular and new features}

Radiology corner continues with a selection of cases curated by Professor John Murchison to challenge your skills in the area; and Physiology masterclass has a contribution on the physiology of respiration in the newborn. I also hope that you are discovering a bit more about the people behind the ERS as this month, ERS Vice President Mina Gaga gives us an insight into her life and work in the Confidences de Salon.

A new feature we have introduced this month takes a look at landmark papers, which serve to remind us of how various practice paradigms we sometimes take for granted in day-to-day care have evolved, challenged or changed the way we diagnose, investigate and manage our patients. I hope you will find these papers interesting and we welcome contributions in the area, particularly from those of you with a historical bent!

\section{Case report competition}

As announced in the December 2015 editorial, we are running a case report competition!
Cite as: Riha RL., Breathe: respiration at the extremes of age. Breathe 2016: 12: 3-4 
The interactive case report remains a fundamental part of the portfolio of Breathe and I would like as many of you as possible to submit your interesting and interactive cases for publication. In this edition, we have an excellent report on the use of novel technology in a life-saving procedure in someone very old. A decade ago, this would not have been possible and the outcome would have been less positive.

Case reports that don't make it into the printed edition of Breathe will be published online as part of our expanding presence and can still be accessed and referenced via PubMed Central; they are guaranteed to reach a large audience either way.

The author of the best case report each year will be awarded their choice of ERS Handbook or ERS Monograph from available stock.

\section{Calling all photographers and artists}

Again, we would like to encourage all readers to assist with enhancing our pages with their creative endeavours. All contributions will be attributed and this might be your chance to have your artwork or photography featured in a publication. Although Breathe isn't Time or The New Yorker, your contribution might still make the front cover!

Corresponding with the XXXI Summer Olympic games in Rio de Janeiro in August this year, the June issue of Breathe will focus on exercise, pulmonary rehabilitation and dyspnoea; use your imagination!

In September this year, we hope to bring out an issue focussing on how we work around the world in respiratory medicine. The September issue of Breathe always has a major presence at the annual ERS International Congress, which will be in London this year (September 5-7, 2016).

Please submit your photos and art related to the world of lung health, disease, clinical care and research to: breathe@ersj.org.uk

Finally, I'd like to thank all contributors to this issue again, as well as the hard-working editorial team who make Breathe a reality.

Enjoy the spring and happy reading!

\section{Conflict of interest}

None declared. 